\title{
DIURNAL PATTERN AND ESTIMATION OF GLOBAL SOLAR RADIATION IN EAST COAST MALAYSIA
}

\author{
M. Mahendran ${ }^{1 *}$, G.C. Lee ${ }^{1}$, A. Shahrani ${ }^{1}$, R. A. Bakar ${ }^{1}$, K. Kadirgama ${ }^{1}$, \\ A. R. Amir ${ }^{1}$ and K.V. Sharma ${ }^{2}$ \\ ${ }^{1}$ Faculty of Mechanical Engineering,Universiti Malaysia Pahang, \\ 26600 Pekan, Pahang, Malaysia \\ *Email: mahen_mu@yahoo.com \\ Phone: +60176673607; Fax: +609424622 \\ ${ }^{2}$ Jawaharlal Nehru Technological University Hyderabad, Kukatpally, \\ Hyderabad - 500085, Andhra Pradesh, India
}

\begin{abstract}
This solar radiation study was undertaken at Pekan campus $\left(3.5^{\circ} \mathrm{N}, 103.4^{\circ} \mathrm{E}\right)$, Faculty of Mechanical Engineering, University Malaysia Pahang. The study focused on the variation of daily global radiation in east coast Malaysia and the development of an empirical model to estimate the monthly average daily global solar radiation on a horizontal surface with Pekan meteorological station data. Solar radiation data were obtained using the weather station which was installed at the site from 2011 to 2013. The patterns were divided into five conditions: clear sky, partially cloudy, fully cloudy, afternoon rain, and northeast monsoon season. It was observed that on a clear sky day in Pekan, the maximum solar insolation was $939 \mathrm{~W} / \mathrm{m}^{2}$ and total solar energy received was $6.51 \mathrm{kWhr} / \mathrm{m}^{2}$. In contrast, on a fully cloudy day the maximum solar insolation was only $30 \mathrm{~W} / \mathrm{m}^{2}$ and total solar energy received was $0.35 \mathrm{kWhr} / \mathrm{m}^{2}$. Subsequently, the developed models were evaluated using statistical analysis. This paper describes an advanced understanding of the daily variation of global solar radiation in east coast Malaysia which may be significant for the design of a solar system. Lastly, use of the Angstrom modified linear models developed is highly recommended to estimate the monthly average daily global solar radiation in Pekan, Pahang and locations with similar solar radiation patterns in east coast Malaysia.
\end{abstract}

Keywords: Solar energy; linear regression; diurnal pattern of global solar radiation.

\section{INTRODUCTION}

The Malaysian government has created an awareness about the depletion of fossil fuels and is diversifying its energy sectors since including renewable energy in the $8^{\text {th }}$ Malaysia Plan (Malaysia, 2001). Solar energy is the renewable energy application with the greatest potential in Malaysia, as most of its terrain receives abundant solar radiation. Knowledge of the daily variation of global solar radiation is a necessity at any particular locality to consider the feasibility of solar energy utilization (Othman et al., 1993; Sathappan, \& Muthucumaraswamy, 2011). In Malaysia, the global solar radiation is mainly influenced by climate conditions such as Asian monsoons, high relative humidity and heavy rainfall. In addition, a preliminary study on solar energy potential on the east coast by Noor et al. (2011) stated that the solar radiation during June 2011 reached around $982 \mathrm{~W} / \mathrm{m}^{2}$. However, the data was insufficient and more data is required to confirm the practicability of solar energy. Recent research by Mahendran et al. 
(2012) on solar energy at Pekan found that the maximum global solar radiation on a clear sky day was $958 \mathrm{~W} / \mathrm{m}^{2}$ and on a partly cloudy day it was $630 \mathrm{~W} / \mathrm{m}^{2}$. Nevertheless, solar radiation measurements are not easily available in all areas and the diurnal pattern of global solar radiation differs from one place to another. Hence, a modeling approach is necessary to estimate global solar radiation from regions with similar climate conditions and solar radiation patterns. A number of researchers in Malaysia have developed regression models to estimate the global solar radiation across the country using different methods (Sopian \& Othman, 1992; Azhari et al., 2008; Muzathik et al., 2011; Nik et al., 2012; Khatib et al., 2012). However, all the authors concluded that the regression coefficients vary for different parts of the country although they have comparable geographical and climatic conditions. Azhari et al. (2008) used satellite images as an alternative method to predict the solar energy in Malaysia and concluded that the northern region of Peninsular Malaysia has high potential for the use of solar energy due to the abundant solar energy received throughout the year, including the month of December. Moreover, Zaharim et al. (2009) used the Box-Jenkins method to predict the global solar radiation at Bangi, Selangor. In contrast, Khatib et al., (2012) used an Artificial Neural Network (ANN) method to predict a clearness index which is used to calculate the global and diffuse solar irradiation in the locality. Furthermore, a comparative study between various Angstrom modified linear empirical models was conducted to establish a suitable model for the state of Terengganu (Muzathik et al., 2011).

Angstrom modified linear regression models based on sunshine hours are widely used to estimate global solar radiation in many parts of the world and these models can also be equipped with some meteorological parameters such as based on the sunshine duration, precipitation, elevation, and latitude (Bakirci, 2009; Duzen \& Aydin, 2012; Li et al., 2010). Some researchers have suggested other empirical relationships in terms of relative humidity and ambient air temperature to estimate the global solar radiation (Togrul \& Onat, 1999; Ertekin \& Yaldiz, 1999). The objective of this paper is to describe the diurnal pattern of global solar radiation in the east coast of Malaysia and to develop suitable models to estimate monthly average daily global solar radiation in Pekan by using meteorological parameters such as the bright sunshine duration, relative humidity and high-low ambient air temperatures.

\section{METHODOLOGY}

\section{Experimental Method}

The global solar radiation, outdoor relative humidity, and rain rate data were measured using the Vantage Pro-2 wireless weather station for a three-year period from 20112013. The wireless sensor transmits the readings to a weather-link data logger which is kept inside a workstation, as shown in Figure 1. Temperature and humidity sensors are located inside the radiation shield. The shield protects the sensors from solar radiation and other sources of radiated and reflected heat. It also includes a rain collector which meets the guidelines of the World Meteorological Organization and reads the amount of rainfall in 0.01 to $0.2 \mathrm{~mm}$ increments (Noor et al., 2011). The data are collected at intervals of five minutes and then averaged and integrated for one day. 


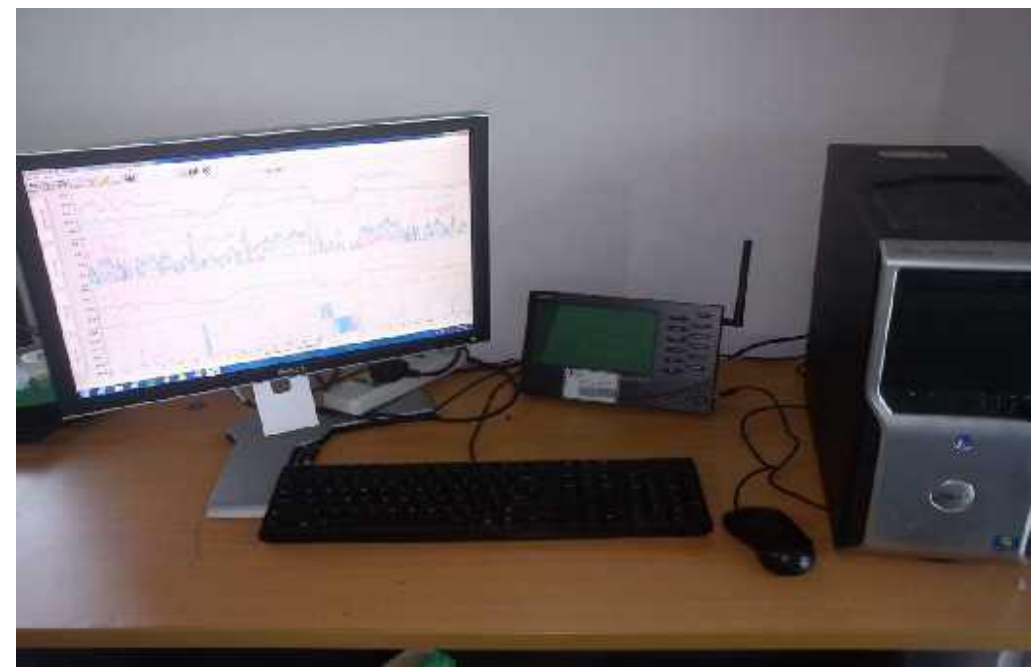

Figure 1. Weather-link data logger workstation.

\section{Empirical Modeling}

In the present work, Angstrom's modified linear model (Sukhatme \& Nayak, 2008) was used to estimate the monthly average of the daily global solar radiation on a horizontal surface $\bar{H}$, where $a_{1}$ and $b_{1}$ are regression coefficients with the actual sunshine hours per day $\bar{N}$, as shown in Eq. (1).

$$
\frac{\bar{H}}{\bar{H}_{o}}=a_{1}+b_{1}\left(\frac{\bar{N}}{\bar{N}_{\max }}\right)
$$

Values of the monthly average of the maximum possible sunshine hours per day $\bar{N}_{\text {max }}$ are calculated from Eq. (2) at the location latitude $\phi$ (Duffie \& Beckman, 2006).

$$
\bar{N}_{\max }=\frac{2}{15} \operatorname{Cos}^{-1}[-\tan \phi \tan \delta]
$$

The extraterrestrial radiation $\bar{H}_{o}$ is obtained from the simplified relationship shown in Eq. (3) and $I_{s c}$ is a solar radiation constant (Sukhatme \& Nayak, 2008).

$$
H_{o}=\frac{24}{\pi} I_{s c}\left[1+0.033 \cos \frac{360 n}{365}\right]\left[\cos \phi \cos \delta \sin \omega_{s}+\omega_{s} \sin \phi \sin \delta\right]
$$

The sunset or sunrise hour angle $\omega_{s}$ and the solar declination angle $\delta$ are defined by the relations in Eq. (4) and Eq. (5) (Gordon, 2001).

$$
\begin{gathered}
\omega_{s}=\cos ^{-1}[-\tan \phi \tan \delta] \\
\delta=23.45 \operatorname{Sin}[360(284+n) / 365]
\end{gathered}
$$


The value is determined on a particular day $n$ of a month. Usually, the $15^{\text {th }}$ of each month is the day $n$ of the month used to determine the solar declination (Sukhatme et al., 2008).

The linear Angstrom's modified model presented by Muzathik et al. (2011) for Terengganu and by Sopian and Othman (1992) for Kota Bharu which was evaluated in this present study is shown in Eq. (6) and Eq. (7) respectively.

$$
\begin{gathered}
\frac{\bar{H}}{\bar{H}_{o}}=0.2207+0.5249\left(\frac{\bar{N}}{\bar{N}_{\max }}\right) \\
\frac{\bar{H}}{\bar{H}_{o}}=0.20+0.47\left(\frac{\bar{N}}{\bar{N}_{\max }}\right)
\end{gathered}
$$

The multiple linear regressions based on latitude, relative humidity, $R_{h}$ and high-low mean temperatures were developed in the present study as shown in Eq. (8) and Eq. (9). The regression coefficients $a_{1}, b_{1}, \ldots, d_{3}$ were obtained from SPSS software using a stepping method for the purpose of estimation.

$$
\begin{gathered}
\frac{\bar{H}}{\bar{H}_{o}}=a_{2} \cos \phi+b_{2}\left(\frac{\bar{N}}{\bar{N}_{\max }}\right) \\
\frac{\bar{H}}{\bar{H}_{o}}=a_{3}+b_{3}\left(\frac{\bar{N}}{\bar{N}_{\max }}\right)+c_{3}\left(R_{h}\right)+d_{3}\left(\frac{T}{T_{\max }}\right)
\end{gathered}
$$

\section{Statistical Analysis}

All models were analyzed with three statistical analyses: the Root Mean Square Error (RMSE), Mean Bias Error (MBE) and percentage error, to evaluate the accuracy of the estimated global solar radiation. The MBE and RMSE provide, respectively, the longterm and short-term performance of an equation. The equation's performance is excellent when the value is small. The percentage error provides the variation in predicted and measured values for each month.

The RMSE is determined using Eq. (10).

$$
R M S E=\left[\frac{1}{n} \sum_{i=1}^{n}\left(H_{i, \text { predict }}-H_{i, \text { measured }}\right)^{2}\right]^{\frac{1}{2}}
$$

The MBE is determined using Eq. (11).

$$
M B E=\frac{1}{n} \sum_{i=1}^{n}\left(H_{i, \text { predict }}-H_{i, \text { measured }}\right)
$$


The percentage error is determined using Eq. (12).

$$
\text { Percentage error }=\left(\frac{H_{i, \text { predict }}-H_{i, \text { measured }}}{H_{i, \text { measured }}}\right) \times 100 \%
$$

\section{RESULTS AND DISCUSSION}

It was observed that the trends of the diurnal pattern of global solar radiation repeatedly maintain a similar pattern for a minimum three days. Therefore, the diurnal pattern was plotted for three days consecutively for global solar radiation, outdoor relative humidity and rain rate. The diurnal patterns of global solar radiation were classified into five patterns as follows:

\section{Global Solar Radiation Pattern for Clear Sky Days}

The global solar radiation pattern on the clear sky days recorded from 18 to 20 August 2012 is shown in Figure 2. It was observed that on 19 August 2012, the maximum instantaneous solar insolation for a clear sky day reached about $939 \mathrm{~W} / \mathrm{m}^{2}$ at 1.25 p.m. and total solar energy received was $6.51 \mathrm{kWhr} / \mathrm{m}^{2}$. The solar energy received was slightly lower, by about 6.4\%, than in west Malaysia (Othman et al., 1993). Consequently, relative outdoor humidity was high at approximately $75-80 \%$ during the daylight, which might obstruct the incoming solar radiation, and at night the outdoor humidity reached $96 \%$. Likewise, the clear sky day radiation pattern was occasional throughout the year in east coast Malaysia. This was due to the strong winds from the sea, cloud cover and high outdoor relative humidity. This pattern is common in the months of March to May and August to October, whereby the high solar energy received on the east coast of Malaysia and similar variation is observed in Figure 7.

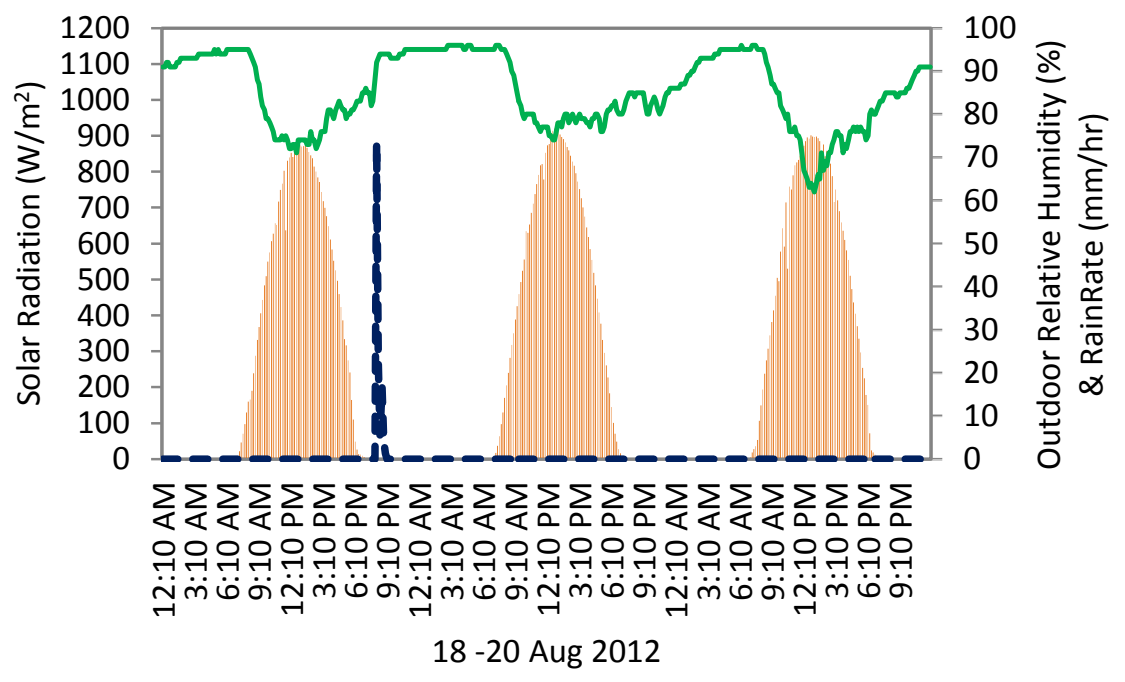

Solar Radiation — Outdoor Relative Humidity - - Rain Rate

Figure 2. Global solar radiation pattern for clear sky days. 


\section{Global Solar Radiation Pattern for Partially Cloudy Days}

Figure 3 shows the global solar radiation pattern for the partially cloudy days as recorded from 1 to 3 December 2012. On 1 December 2012, the average solar insolation was less than $425 \mathrm{~W} / \mathrm{m}^{2}$ and total solar energy received was $2.21 \mathrm{kWhr} / \mathrm{m}^{2}$. The contrary relationship of relative outdoor humidity and global solar radiation can be observed clearly at a number of points on partially cloudy days. This pattern is unpredictable, and the solar energy received may differ with the degree of cloudiness at the location.

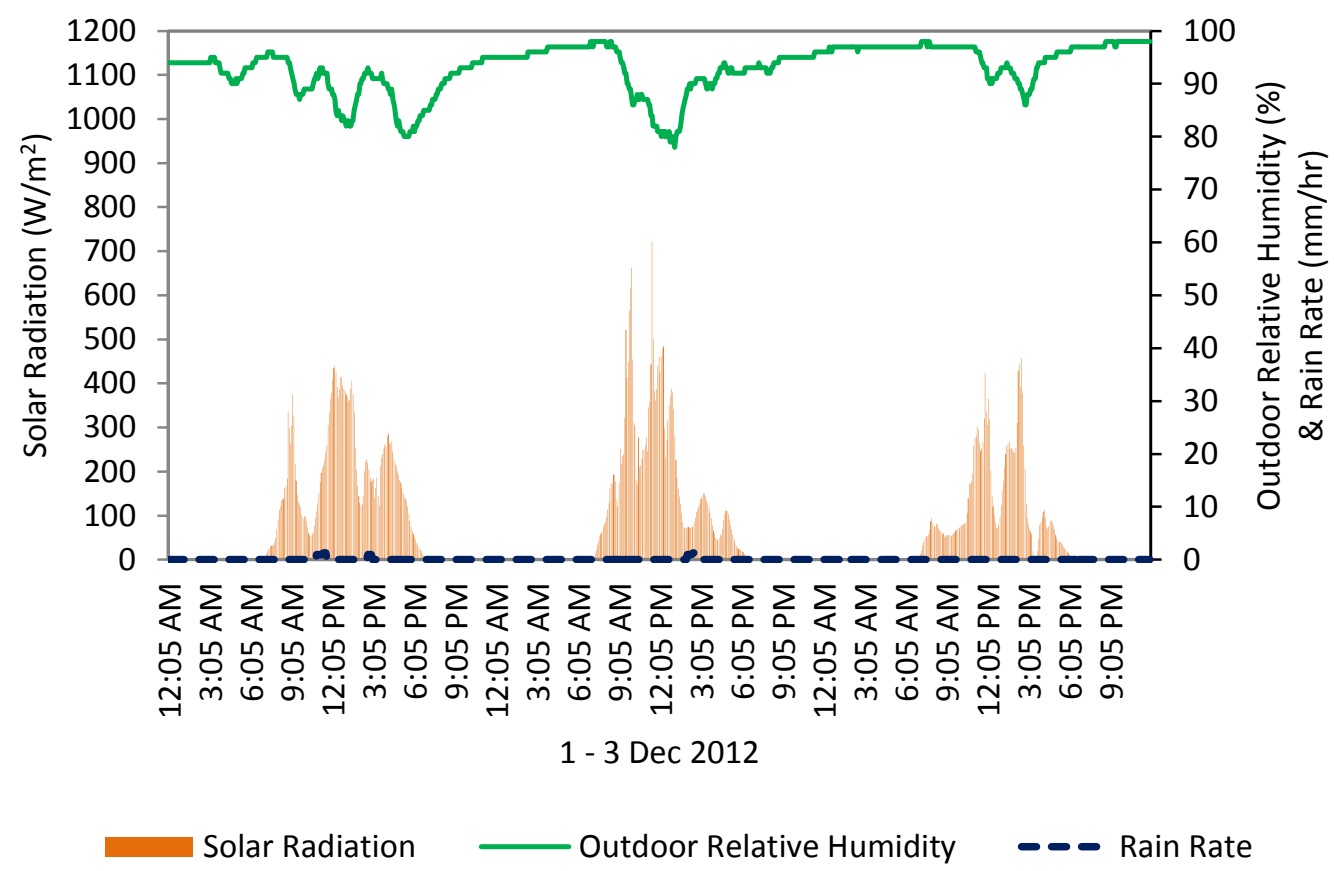

Figure 3. Global solar radiation pattern for partially cloudy days.

\section{Global Solar Radiation Pattern for Fully Cloudy Days}

The global solar radiation pattern for the fully cloudy days recorded from 23 to 25 December 2012 is shown in Figure 4. This pattern only occurs when there is cloud cover for the entire day, from early morning until late afternoon, sometimes with occasional rain. It was noticed that the relative outdoor humidity was very high, ranging from $90-98 \%$, and it also reached $99 \%$, which was near to the saturation point of the measuring sensor although there was no rain during this pattern. On 24 December 2012, the maximum solar insolation received was $30 \mathrm{~W} / \mathrm{m}^{2}$ and total solar energy received was $0.35 \mathrm{kWhr} / \mathrm{m}^{2}$. The solar energy value was only $5.38 \%$ of that of a clear sky day. The average insolation for the entire day was less than $200 \mathrm{~W} / \mathrm{m}^{2}$ for 23 and 25 December 2012 and total solar energy received was 1.74 and $0.46 \mathrm{kWhr} / \mathrm{m}^{2}$ respectively. This pattern of solar radiation is unusual but it can be observed during the winter solstice when the sun is at its most southerly position. 


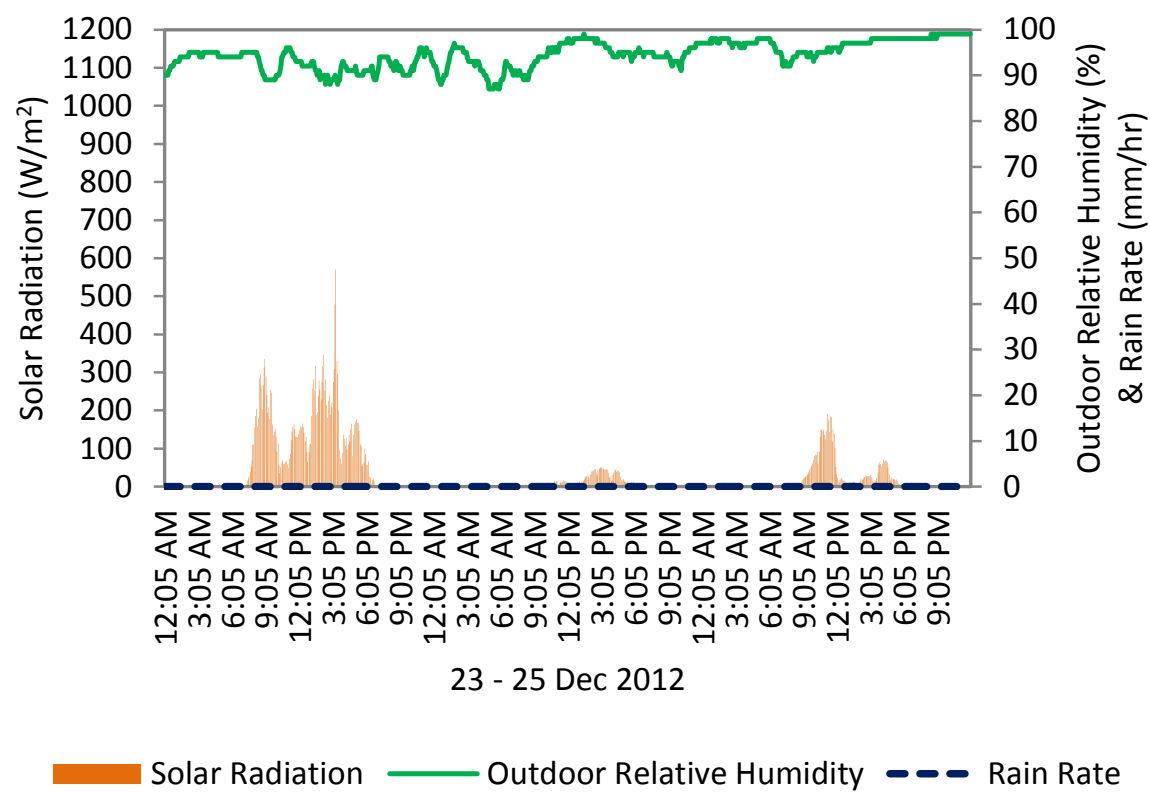

Figure 4. Global solar radiation pattern for fully cloudy days.

\section{Global Solar Radiation Pattern for Afternoons on Rainy Days}

Figure 5 shows the global solar radiation pattern for the afternoons on rainy days recorded from 6 to 8 October 2012. From the figure, the maximum solar insolation during midday on 7 October 2012 was $1048 \mathrm{~W} / \mathrm{m}^{2}$. Then, heavy rain started to fall in the late afternoon with a peak rain rate of about $500 \mathrm{~mm} / \mathrm{hr}$, which was the highest recorded in 2012, and it lasted for 2 hours. Total solar energy received for the day was $4.07 \mathrm{kWhr} / \mathrm{m}^{2}$. Similar patterns can be observed on 6 and 8 October 2012 with peak rain rates of $150 \mathrm{~mm} / \mathrm{hr}$ and $50 \mathrm{~mm} / \mathrm{hr}$ respectively. In general, the probability of rain falling in the afternoon or at dusk is due to convection currents in the morning.

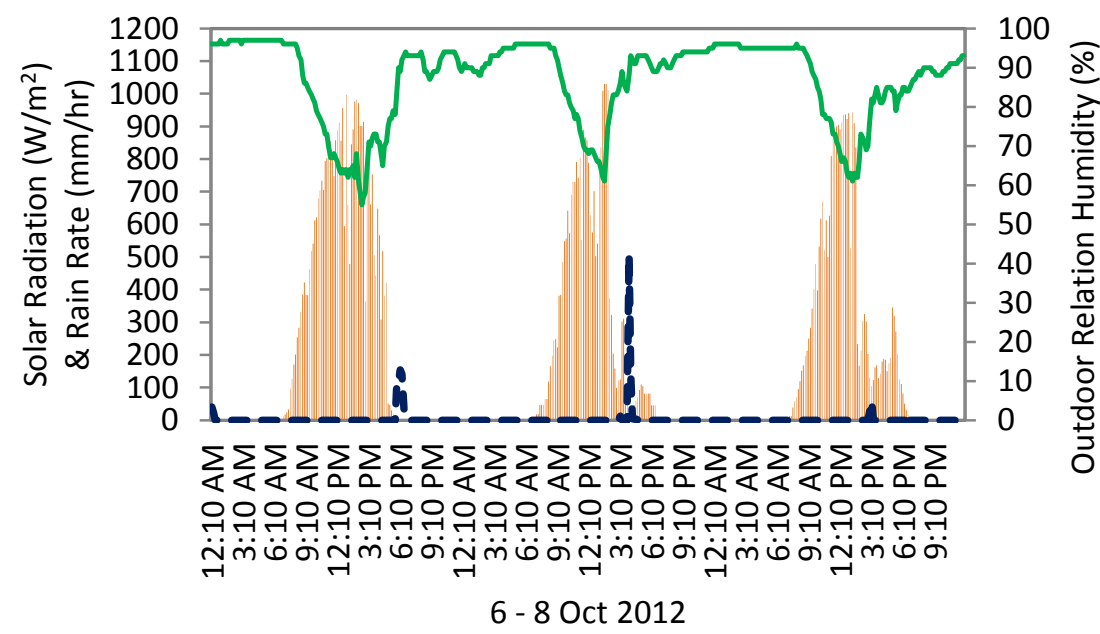

Solar Radiation - _ - Rain Rate _ Outdoor Relative Humidity

Figure 5. Global solar radiation pattern for afternoons on rainy days. 


\section{Global Solar Radiation Pattern for the Northeast Monsoons Rain Season Days}

The global solar radiation pattern for the northeast monsoons rain season days recorded from 19 to 21 January 2013 is shown in Figure 6. The northeast monsoon brings rain and cloud to the east coast from November to March. On 20 January 2013, the maximum solar insolation was $1051 \mathrm{~W} / \mathrm{m}^{2}$ and total solar energy received was 1.22 $\mathrm{kWhr} / \mathrm{m}^{2}$. However, a sudden peak in solar insolation may have been caused by the refraction and reflection of solar radiation by the cloud and particles in the air (Othman et al., 1993) or the clear sky that occurred immediately after the rain stopped for a moment. Total solar energy received on 19 and 21 January 2012 was 1.63 and 2.44 $\mathrm{kWhr} / \mathrm{m}^{2}$ respectively. The average rain rate for those entire days was less than 3.8 $\mathrm{mm} / \mathrm{hr}$ and the relative outdoor humidity was approximately $90-95 \%$.

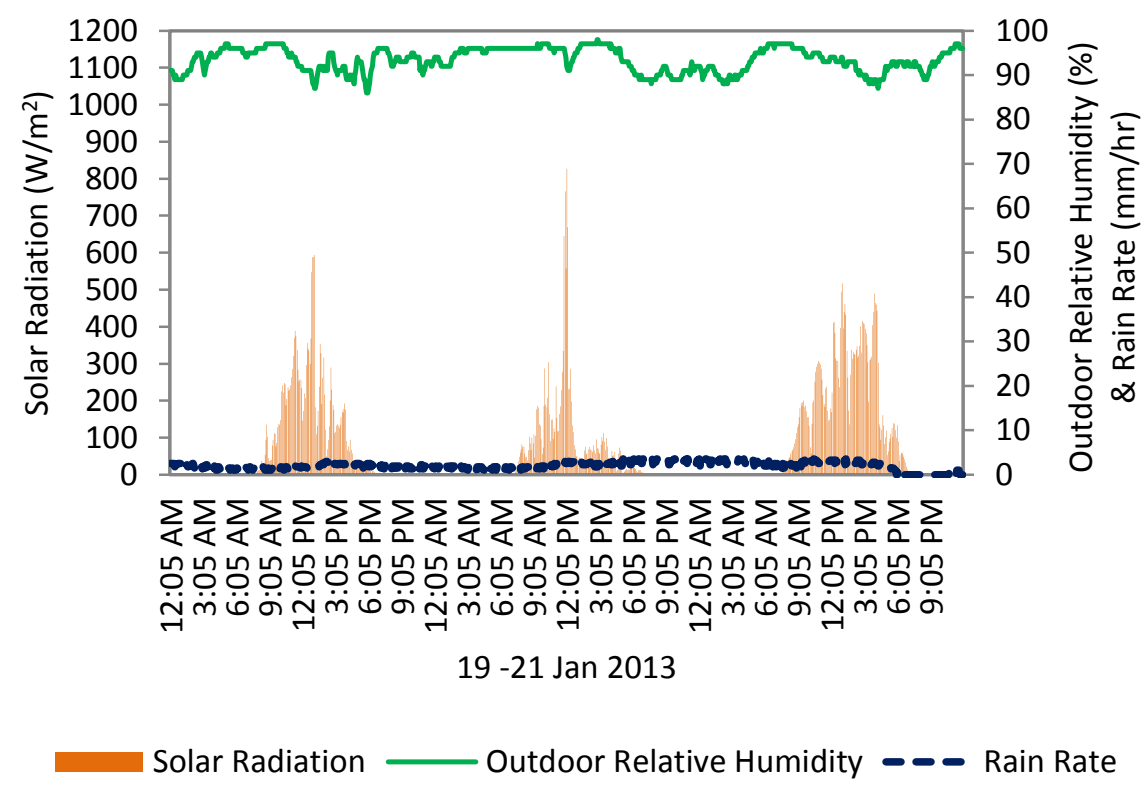

Figure 6. Global solar radiation pattern for the northeast monsoons rain season days.

\section{Regression Modeling}

The regression parameters for the estimation of monthly average daily global solar radiation are listed in Table 1 . The parameters were obtained from observations at Pekan meteorology station from 2006 to 2012.

The Angstrom's modified linear regressions developed for Pekan are shown in Eqs. (13)-(15).

$$
\begin{gathered}
\frac{\bar{H}}{\bar{H}_{o}}=0.22+0.47 \frac{\bar{N}}{\bar{N}_{\max }} \\
\frac{\bar{H}}{\bar{H}_{o}}=0.22 \cos \phi+0.47\left(\frac{\bar{N}}{\bar{N}_{\max }}\right)
\end{gathered}
$$




$$
\frac{\bar{H}}{\bar{H}_{o}}=0.35+0.41\left(\frac{\bar{N}}{\bar{N}_{\max }}\right)+0.065\left(R_{h}\right)-0.206\left(\frac{T}{T_{\max }}\right)
$$

Table 1. Regression parameters for the estimation of monthly average daily global solar radiation.

\begin{tabular}{lcccccc}
\hline \multicolumn{1}{c}{ Month } & $\begin{array}{c}\bar{H} \\
\left(\mathrm{kWhr} / \mathrm{m}^{2}\right)\end{array}$ & $\begin{array}{c}\bar{H}_{o} \\
\left(\mathrm{kWhr} / \mathrm{m}^{2}\right)\end{array}$ & $\begin{array}{c}\bar{N} \\
\bar{N}_{\max }\end{array}$ & $\begin{array}{c}\bar{H} \\
\bar{H}_{o}\end{array}$ & $R_{h}$ & $\frac{T_{L}}{T_{H}}$ \\
\hline January & 3.829 & 9.691 & 0.379 & 0.395 & 0.809 & 0.783 \\
February & 4.536 & 10.165 & 0.492 & 0.446 & 0.783 & 0.759 \\
March & 4.840 & 10.467 & 0.534 & 0.462 & 0.806 & 0.747 \\
April & 5.160 & 10.365 & 0.595 & 0.498 & 0.800 & 0.726 \\
May & 4.879 & 9.953 & 0.554 & 0.490 & 0.803 & 0.713 \\
June & 4.458 & 9.658 & 0.486 & 0.462 & 0.798 & 0.712 \\
July & 4.457 & 9.749 & 0.482 & 0.457 & 0.802 & 0.711 \\
August & 4.928 & 10.125 & 0.559 & 0.487 & 0.795 & 0.708 \\
September & 4.903 & 10.362 & 0.549 & 0.473 & 0.795 & 0.702 \\
October & 4.597 & 10.194 & 0.502 & 0.451 & 0.808 & 0.722 \\
November & 4.061 & 9.766 & 0.420 & 0.416 & 0.833 & 0.749 \\
December & 4.034 & 9.503 & 0.426 & 0.424 & 0.838 & 0.783 \\
\hline
\end{tabular}

Figure 7 shows the variation of actual to maximum sunshine hour, $\bar{N} / \bar{N}_{\max }$ and the clearness index, $\bar{H} / \bar{H}_{o}$ for Pekan. The months of November to March show fewer hours of sunshine and heavy cloudy cover similar to the pattern in Figure 4, which was discussed earlier. The $\bar{N} / \bar{N}_{\max }$ goes as low as 0.379 in January, which was due to the northeast monsoon season on the east coast of Malaysia during this period.

The monthly average daily global solar radiation estimated values using Eqs. (13)-(15) for Pekan are given in Table 2, along with the measured values and the estimated values from the models of Sopian et al. (1992) and Muzathik et al. (2011), Eqs. (6) and (7) respectively. The percentage errors, RMSE, and MBE of the models are shown in Table 3. The RSME and MBE of Eq. (6) were 0.285 and 0.272, while for Eq. (7) they were 0.219 and -0.209 . The lower values of RSME and MBE noticed in the present developed models were nearly zero. The minimum and maximum percentage errors in the Muzathik et al. (2011) model were $3.10 \%$ and $8.32 \%$, whereas in the Sopian et al. (1992) model they were $-2.5 \%$ and $7.2 \%$. The present developed models, Eq. (13) and Eq. (14), have the maximum percentage errors of about $2.83 \%$ and $2.92 \%$ respectively, for the month of June. However, the model developed in terms of relative humidity and high-low air ambient temperature, Eq. (15), shows a lower percentage error of about $-1.53 \%$ for the same month. Therefore, there is a significant influence from meteorology parameters such as relative humidity and air temperature on the estimation of global solar radiation. The predicted values from the present developed models using Eqs. (13)-(15) were compared with the measured value of monthly average daily global solar radiation as shown in Figure 8. All the developed models' estimated values are in excellent agreement with the measured values in Pekan. This finding is also supported by the RSME and MBE values, which are nearly zero. In 
addition, Figure 9 shows that the present developed and established models have good agreement with the measured and estimated values in Pekan, as the models are in the range of $\pm 10.0 \%$. Hence, this range is acceptable for the different types of weather conditions at the particular locality.

Table 2. Estimation of monthly average daily global solar radiation from various models for Pekan.

\begin{tabular}{lccccccc}
\hline \multirow{1}{*}{ Month } & $\begin{array}{c}\bar{H} \\
\text { Measured }\end{array}$ & $\begin{array}{c}\text { Muzathik } \\
\text { et al. 2011 } \\
\text { Eq. (6) }\end{array}$ & $\begin{array}{c}\text { Sopian } \\
\text { et al. }\end{array}$ & Eq.(13) & Eq.(14) & Eq.(15) \\
\hline January & 3.829 & 4.064 & 3.662 & 3.856 & 3.852 & 3.842 \\
February & 4.536 & 4.870 & 4.384 & 4.588 & 4.584 & 4.537 \\
March & 4.84 & 5.243 & 4.719 & 4.929 & 4.924 & 4.892 \\
April & 5.160 & 5.523 & 4.970 & 5.178 & 5.173 & 5.144 \\
May & 4.879 & 5.090 & 4.581 & 4.780 & 4.776 & 4.801 \\
June & 4.458 & 4.596 & 4.138 & 4.332 & 4.328 & 4.390 \\
July & 4.457 & 4.619 & 4.159 & 4.354 & 4.350 & 4.420 \\
August & 4.928 & 5.207 & 4.687 & 4.889 & 4.885 & 4.912 \\
September & 4.903 & 5.271 & 4.744 & 4.951 & 4.947 & 4.994 \\
October & 4.597 & 4.936 & 4.444 & 4.648 & 4.644 & 4.685 \\
November & 4.061 & 4.308 & 3.881 & 4.076 & 4.072 & 4.122 \\
December & 4.034 & \multicolumn{7}{c}{3.801} & 3.992 & 3.988 & 3.969 \\
\hline
\end{tabular}

All numerical values are in units of $\mathrm{kWhr} / \mathrm{m}^{2}$

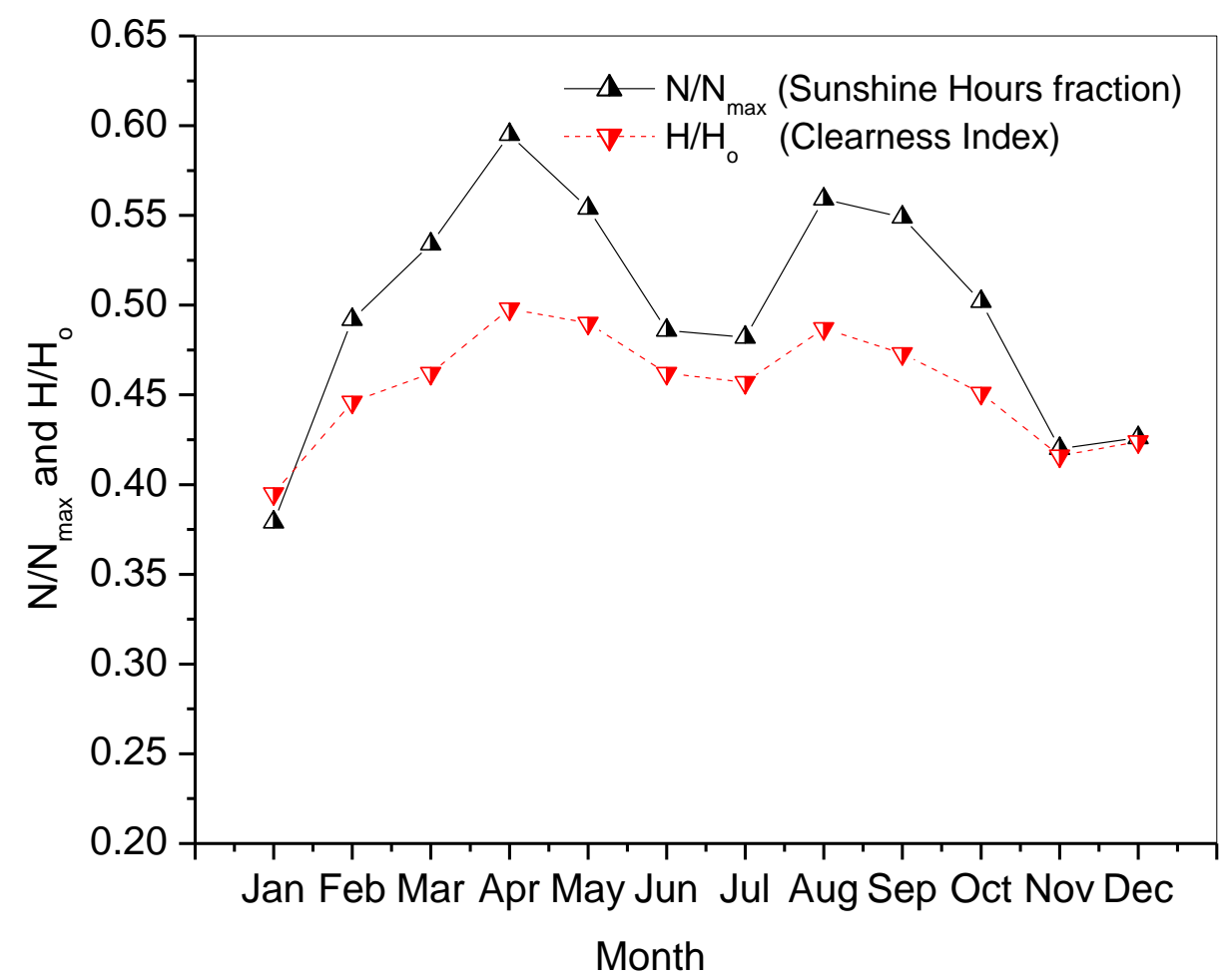

Figure 7. Variation of actual to maximum sunshine hour, $\bar{N} / \bar{N}_{\max }$ and the clearness index, $\bar{H} / \bar{H}_{o}$ for Pekan. 
Table 3. Percentage error, RMSE, and MBE of the models.

\begin{tabular}{cccccc}
\hline Month & $\begin{array}{c}\text { Muzathik } \\
\text { et al. 2011 } \\
\text { Eq. (6) }\end{array}$ & $\begin{array}{c}\text { Sopian et } \\
\text { al. 1992 } \\
\text { Eq. (7) }\end{array}$ & Eq.(13) & Eq.(14) & Eq.(15) \\
\hline January & $6.15 \%$ & $-4.3 \%$ & $0.71 \%$ & $0.61 \%$ & $0.35 \%$ \\
February & $7.35 \%$ & $-3.3 \%$ & $1.14 \%$ & $1.05 \%$ & $0.02 \%$ \\
March & $8.32 \%$ & $-2.5 \%$ & $1.83 \%$ & $1.74 \%$ & $1.07 \%$ \\
April & $7.04 \%$ & $-3.7 \%$ & $0.34 \%$ & $0.26 \%$ & $-0.31 \%$ \\
May & $4.32 \%$ & $-6.1 \%$ & $-2.03 \%$ & $-2.11 \%$ & $-1.60 \%$ \\
June & $3.10 \%$ & $-7.2 \%$ & $-2.83 \%$ & $-2.92 \%$ & $-1.53 \%$ \\
July & $3.63 \%$ & $-6.7 \%$ & $-2.31 \%$ & $-2.40 \%$ & $-0.84 \%$ \\
August & $5.67 \%$ & $-4.9 \%$ & $-0.78 \%$ & $-0.87 \%$ & $-0.32 \%$ \\
September & $7.50 \%$ & $-3.2 \%$ & $0.98 \%$ & $0.90 \%$ & $1.86 \%$ \\
October & $7.37 \%$ & $-3.3 \%$ & $1.10 \%$ & $1.01 \%$ & $1.92 \%$ \\
November & $6.09 \%$ & $-4.4 \%$ & $0.37 \%$ & $0.27 \%$ & $1.49 \%$ \\
December & $4.62 \%$ & $-5.8 \%$ & $-1.05 \%$ & $-1.15 \%$ & $-1.61 \%$ \\
RSME & 0.285 & 0.219 & 0.069 & 0.069 & 0.057 \\
MBE & 0.272 & -0.209 & -0.009 & -0.013 & 0.002 \\
\hline
\end{tabular}

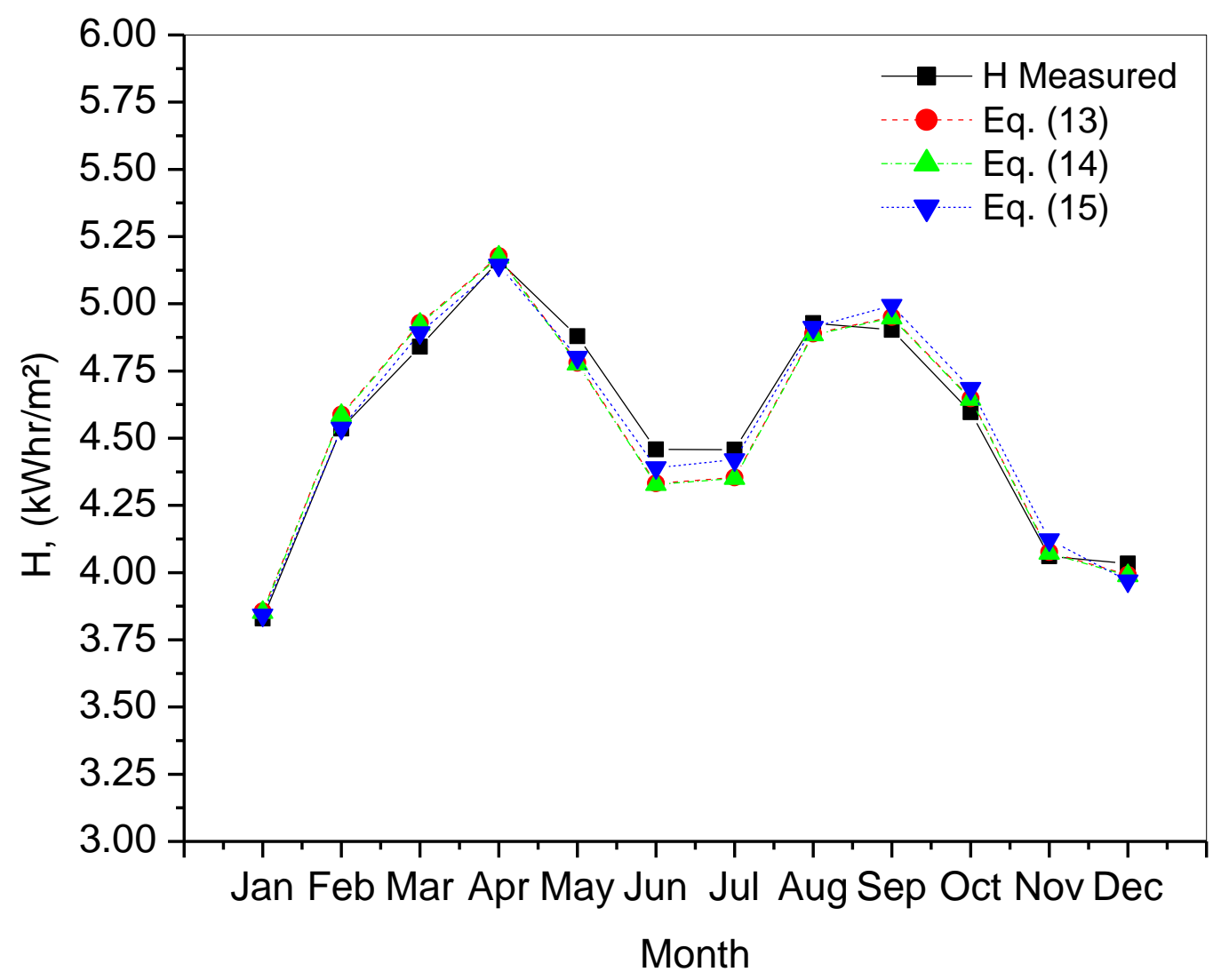

Figure 8. Comparison between estimated values of present developed models Eq. (13) (15) and measured value of global solar radiation in Pekan. 


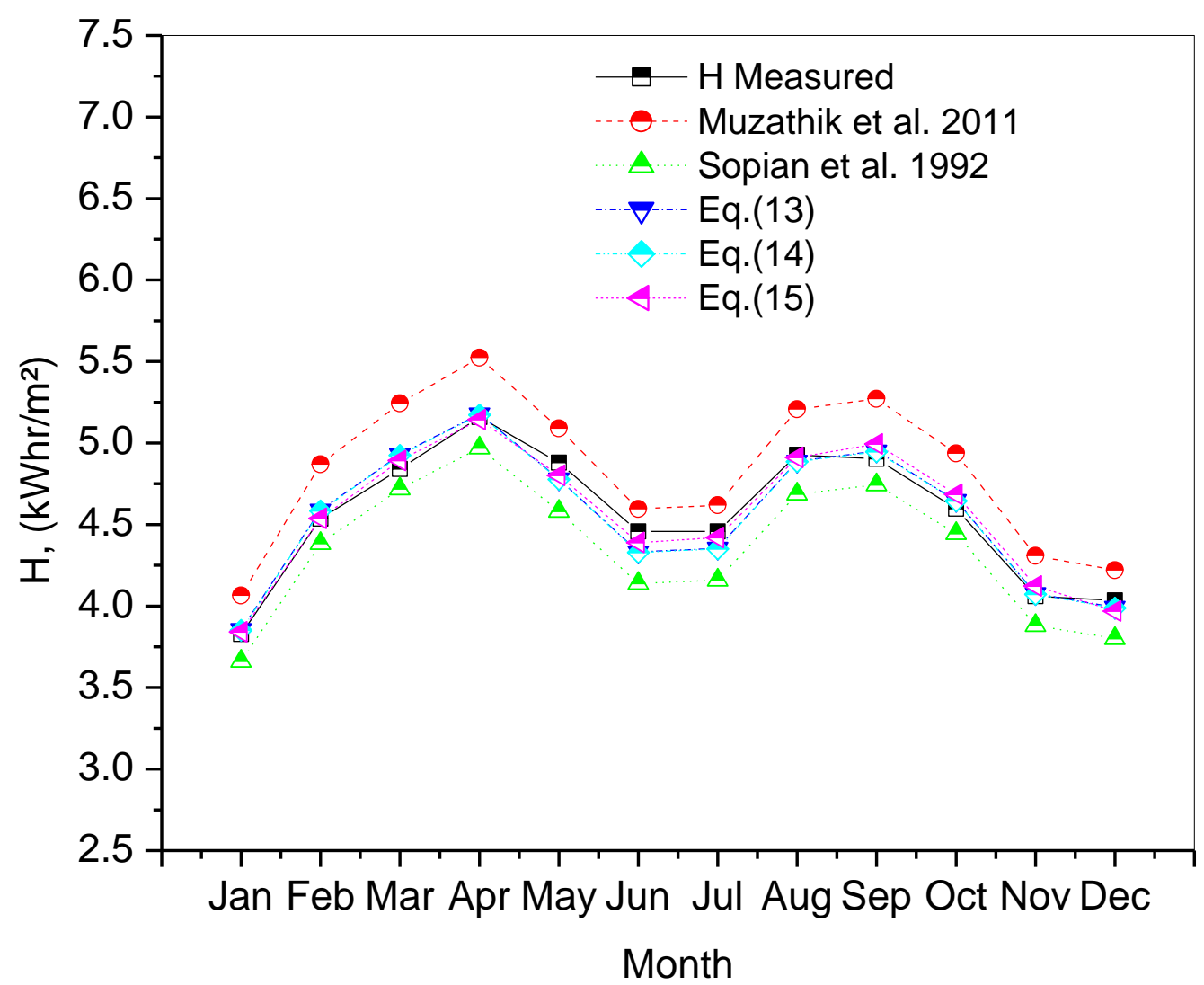

Figure 9. Comparison between estimated values of present developed and established models with measured value of global solar radiation in East Coast Malaysia.

\section{CONCLUSIONS}

The knowledge of global solar radiation patterns is extremely important in designing a solar system to utilize the available solar energy efficiently. The five described patterns were generally observed in the east coast region. Information on these patterns is very useful especially to the local community and solar system manufacturers to enable them to employ solar energy in east coast Malaysia and locations with similar weather conditions. The orientation of solar panels and collectors should also be considered for the northeast monsoon period from November to March in order to optimize the solar energy throughout the year. Use of the developed regression models in Eq. (13) and Eq. (15) is highly recommended to estimate the monthly average daily global solar radiation in Pekan, Pahang and locations with similar solar radiation patterns in east coast Malaysia.

\section{ACKNOWLEDGMENTS}

The authors would like to thank the Faculty of Mechanical Engineering in Universiti Malaysia Pahang (UMP) and Universiti Malaysia Pahang for financial support under RDU110327. The authors are also grateful to the Malaysia Meteorological Department for the data. 


\section{REFERENCES}

Azhari, A. W., Sopian, K. Zaharim, A., \& Ghoul, M. A. (2008). A new approach for predicting solar radiation in tropical environment using satellite images - case study of Malaysia. WSEAS Transactions on Environment and Development, 4, 373-378.

Bakirci, K. (2009). Correlations for estimation of daily global solar radiation with hours of bright sunshine in Turkey. Energy, 34, 485-501.

Duffie, J. A. \& Beckman, W. A. (2006). Solar engineering of thermal processes. New York: Wiley-Interscience.

Duzen, H. \& Aydin, H. (2012). Sunshine-based estimation of global solar radiation on horizontal surface at Lake Van region Turkey. Energy Conversion and Management, 58, 35-46

Ertekin, C. \& Yaldiz, O. (1999). Estimation of monthly average daily global radiation on horizontal surface for Antalya (Turkey). Renewable Energy, 17, 95-102.

Gordon, J. (2001). Solar energy: the state of the art. United Kingdom: ISES Position Papers.

Khatib, T., Mohamed, A., Sopian, K., \& Mahmoud, M. (2012). Solar energy prediction for Malaysia using Artificial Neural Networks. International Journal of Photoenergy, Article ID: 419504, DOI:10.1155/2012/419504.

Li, M. F., Liu, H. B., Guo, P. T., \& Wu, W. (2010). Estimation of daily solar radiation from routinely observed meteorological data in Chongqing, China. Energy Conversion Management, 51, 2575-2579.

Mahendran, M., Lee, G. C., Sharma, K. V., Shahrani, A., \& Bakar, R. A. (2012). Performance evaluation of evacuated tube solar collector using waterbased titanium oxide $\left(\mathrm{TiO}_{2}\right)$ nanofluid. Journal of Mechanical Engineering \& Sciences, 3, 301-310.

Malaysia (2001) $8^{\text {th }}$ Malaysia Plan 2001-2005.

Muzathik, A. M., Nik, W. B. W., Ibrahim, M. Z., Samo, K. B., Sopian, K., \& Alghoul, M. A. (2011). Daily global solar radiation estimate based on sunshine hours. International Journal of Mechanical and Materials Engineering, 6, 75-80.

Nik, W. B. W., Ibrahim, M. Z., Samo, K. B., \& Muzathik, A. M. (2012). Monthly mean hourly global solar radiation estimation. Solar Energy, 86, 379-387.

Noor, M. M., Amirruddin, A. K., Kadirgama, K., \& Sharma, K. V. (2011). The potential of wind and solar energy in Malaysia east coast: Preliminary study at Universiti Malaysia Pahang (UMP). Transactions of the Wessex Institute, Paper ID: 22994, DOI: 10.2495/RAV110431.

Othman, M. Y. H., Sopian, K., Yatim, B., \& Dalimin, M. N. (1993). Diurnal pattern of global solar radiation in the tropics: A case study in Malaysia. Renewable Energy, 3, 741-745.

Sathappan, K. E., \& Muthucumaraswamy, R. (2011). Radiation effects on exponentially accelerated vertical plate with uniform mass diffusion. International Journal of Automotive and Mechanical Engineering, 3, 341-349.

Sopian, K. \& Othman, M. Y. (1992). Estimation of monthly average daily global solar radiation in Malaysia. Renewable Energy, 2, 319-325.

Sukhatme, S. P. \& Nayak, J. (2008). Solar energy: principles of thermal collection and storage. Tata Singapore: McGraw-Hill. 
Togrul, I. T. \& Onat, E. (1999). A study for estimating solar radiation in Elazig using geographical and meteorological data. Energy Conversion and Management, 40, 1577-1584.

Zaharim, A., Razali, A. M., Gim, T. P., \& Sopian, K. (2009). Time series analysis of solar radiation data in the tropics. European Journal of Scientific Research, 25, 672-678. 